\title{
Analysis of changes in post-seismic landslide distribution and its effect on building reconstruction
}

\author{
W. T. Yang ${ }^{1,3,4,5}$, M. Wang ${ }^{1,5}$, N. Kerle ${ }^{3}$, C. J. Van Westen ${ }^{3}$, L. Y. Liu ${ }^{2,5}$, and P. J. Shi ${ }^{1,2,5}$ \\ ${ }^{1}$ State Key Laboratory of Earth Surface Processes and Resource Ecology, Beijing Normal University, Beijing, China \\ ${ }^{2}$ Key Laboratory of Environmental Change and Natural Disaster, MOE, Beijing Normal University, Beijing, China \\ ${ }^{3}$ Department of Earth System Analysis, Faculty of Geo-Information and Earth Observation (ITC), University of Twente, \\ Enschede, the Netherlands \\ ${ }^{4}$ School of Soil and Water Conservation, Beijing Forestry University, Beijing, China \\ ${ }^{5}$ Academy of Disaster Reduction and Emergency Management, Beijing Normal University, Beijing, China \\ Correspondence to: M. Wang (wangming@bnu.edu.cn) and P. J. Shi (spj@bnu.edu.cn)
}

Received: 12 August 2014 - Published in Nat. Hazards Earth Syst. Sci. Discuss.: 27 August 2014

Accepted: 11 March 2015 - Published: 10 April 2015

\begin{abstract}
Six years after the devastating $M_{\mathrm{s}}$ 8.0 Wenchuan earthquake, new landslides, debris flows, and flash floods still occur frequently in the earthquake-stricken regions. This shows that the geological hazards that occur after a major earthquake in a mountainous environment can be a long-term threat. However, post-earthquake reconstruction and relocation of local residents often neglect this evolving threat, and its interaction with existing and rebuilt houses has not been well studied. Here we show that the evolving mountain environment, including the changed geographic distribution of new landslides and the continuously uplifting riverbed, creates emerging risks for existing and rebuilt houses. We use spatial analysis of landslide debris and the location of houses from high-resolution images and field survey in the study area and find that new landslides and the houses rebuilt after the Wenchuan earthquake have a similar trend of moving to lower elevations, gentler slopes, and closer to rivers. This study confirms that the persistent downward movement of landslide debris has rapidly filled up riverbeds over the past 6 years. The elevated riverbeds make the study area extremely susceptible to flash floods, creating further risks to newly rebuilt houses that are closer to the river. We highlight the often neglected dynamic process that involves changes in the natural environment and man-made constructions and their interaction. This dynamic process requires long-term monitoring and adaptive management of mountainous regions after major earthquakes that can fully consider the so-
\end{abstract}

phisticated evolving risks caused by the changing environment, exposure, and vulnerability in the region.

\section{Introduction}

Geohazards after major mountain earthquakes not only pose an imminent threat to lives by coseismic landslides and quake-dam breach floods (Cui et al., 2011; Fan et al., 2012a) but may also persist for more than 10 years before recovery to pre-earthquake conditions (Cui et al., 2011; Huang, 2011). Post-seismic reconstruction often occurs quickly during that time, while geodynamic activity still continues. The lack of understanding between a changing mountain environment and reconstruction of buildings in the affected areas results in more damage in the years following the earthquake (Cheng et al., 2005; Sudmeier-Rieux et al., 2011).

The evolution of post-seismic landslides is a complex issue that may have distinct patterns in different geographic settings. Studying typhoon events before and after the ChiChi earthquake, Lin et al. (2006) found that the density of post-earthquake rainfall-induced landslides increased significantly compared to those of pre-seismic typhoon events, and newly triggered landslides were located on steeper slopes. However, research on spatiotemporal landslide changes after the 2005 Kashmir earthquake showed that apart from the heaviest monsoon seasons, landslide changes are insignifi- 
cant 2 years after the earthquake (Khattak et al., 2010; Saba et al., 2010; Khan et al., 2013).

Considering the large number and complex types of landslides triggered by the Wenchuan earthquake (Gorum et al., 2011), it is difficult for most post-seismic landslide-affected slopes to fully revert to the pre-seismic condition covered by stable vegetation (Lin et al., 2008; Wang et al., 2014). Furthermore, the large number of earthquake-related landslides near the drainage system may have an effect on postseismic sediment flux over a decadal timescale (Fan et al., 2012b). On a regional scale, erosion caused by earthquakerelated landslides has a long-lasting effect on the landscape (Keefer, 1994; Dadson et al., 2003). Based on studies of sediments in check-dam basins, Koi et al. (2008) concluded that mountain earthquakes can lead to high sediment discharge for 100 years. Chen (2009) studied the sedimentary impacts of coseismic and post-seismic landslides in rainfall events in the Tachia River basin after the Chi-Chi earthquake and found that landslides provided materials for numerous debris flows, filled up the riverbed, and led to flash floods inundating downstream areas. After the Wenchuan earthquake, Cui et al. (2011) and Huang (2011) predicted that the debris generated by landslides may evolve into major postseismic geohazards, such as debris flows, which can last for at least 10 years before recovery to the pre-seismic conditions. Materials generated from mountain earthquakes more than 100 years ago may have led to the disasters that occurred in Zhouqu, China, that claimed more than 1700 lives in 2010 (Xin, 2010).

Post-disaster reconstruction always occurs almost immediately following a disaster but can have long-term impacts for the people affected (Jha and Duyne, 2010). Furthermore, most studies on post-seismic reconstruction have mainly been carried out in urban areas. After major earthquake disasters, the lifeline systems are regarded as the most urgent infrastructure to recover in order to reduce the impact of the disaster in cities (Kozin and Zhou, 1990). Building reconstruction after the 1999 Chi-Chi and the 1994 Northridge earthquakes was completed 35 months after the main earthquake (Wu and Lindell, 2004), whereas the reconstruction was much faster for the 2008 Wenchuan earthquake. Because of the dominant role played by the central Chinese government, reconstruction of rural housing was virtually completed 1 year after the main earthquake, which was 2 years less than the overall plan (Dunford and Li, 2011). Housing recovery usually takes place in four stages from emergency shelter to permanent housing (Quarantelli, 1982). Accelerated reconstruction of permanent housing is often selected at the location of temporary housing (UNDRO, 1982), which is usually built in the chaos following the disaster using incomplete information (Johnson, 2007).

The reconstruction of housing and roads has an impact on mountain geohazards after a major earthquake (Atta-urRahman et al., 2010, 2013; Sudmeier-Rieux et al., 2011). After the 2005 Pakistan earthquake, Khattak et al. (2010) ob- served that the locations that showed an increase in landslides were situated along rivers and/or roads. After the Wenchuan earthquake, the lack of reconstruction space in the mountainous regions caused some rebuilt infrastructures to be placed in the hazardous area. Because of the rough terrain in the study area, most buildings and other infrastructure before and after the earthquake were located along rivers. Several quake-dam breaches and landslides along the riverbank provided sediment that caused the rising and widening of the riverbed. The competition for space between housing reconstruction and sediment transportation posed further risks in this area.

To understand post-earthquake landslide-related disasters, analysis of hazards, elements at risk, and other related factors should be integrated (Shi, 1996; Schwendtner et al., 2013). The typology, location, and intensity of geohazards are still changing and the hasty reconstruction after the major mountain earthquake does not take all factors into consideration. Therefore, it would be impossible to understand post-seismic disasters from single studies of changing mountain hazards or the study of change patterns of reconstructed infrastructures. This paper will use a small basin in the Wenchuan area to study the effect of changing earthquake-related landslides, the varying patterns of reconstructed houses, and their interaction to understand the mechanism of mountain disasters after major earthquakes.

\section{Data and methods}

The study area is part of east Pingwu County in the lower part of the Hongxi River watershed, which is a first-order tributary on the right side of the upper Fujiang River in northern Sichuan, as shown in Fig. 1. This region experienced Modified Mercalli Intensity scale X and XI and suffered extensive damage with more than $60 \%$ of the housing collapsing and most of the remaining structures being heavily destroyed during the 2008 Wenchuan earthquake (Mao et al., 2009). The main fault of the Wenchuan earthquake began near the epicenter close to the town of Yingxiu and ran more than $200 \mathrm{~km}$ northeast through this watershed, with maximum vertical and horizontal surface rupture offsets of 6.5 and $4.9 \mathrm{~m}$, respectively (Xu et al., 2009). Most buildings within $50 \mathrm{~m}$ of this surface rupture during the earthquake suffered damage ranging from serious damage to total collapse. More than $30 \%$ of the buildings were found to have collapsed within $1000 \mathrm{~m}$ of the surface rupture in the Nanba region (Zhao et al., 2012). The Hongxi River drains the watershed from the northeast to the southwest, with its major watercourse running parallel to the fault.

After the 2008 earthquake, landslide debris in the watershed experienced dramatic changes with some small, shallow landslide debris being re-vegetated and the shape of most of the large landslides evolving into flow-like morphology over the following years. The morphological change was caused 
Table 1. Inventory of images used in the study.

\begin{tabular}{llll}
\hline Time & Sensor & Resolution/m & Color \\
\hline 8 November 2002 & IKONOS & $0.6 / 2.4$ & Pan/multi \\
5 September 2006 & SPOT5 & $2.5 / 10$ & Pan/multi \\
4 June 2008 & SPOT5 & $2.5 / 10$ & Pan/multi \\
27 August 2011 & WorldView-2 & $0.5 / 2$ & Pan/multi \\
24 April 2012 & WorldView-1 & 0.5 & Pan \\
\hline
\end{tabular}

by rainfall events during the summer season that carried the debris of the landslides down to lower sites. Landslide debris becomes more complex by merging debris from different landslide bodies within the same valley.

Rebuilt houses, landslides, and riverbeds from different years were manually analyzed from high-resolution images, and field validation was carried out to confirm the mapping results. Five 1-A level high-resolution satellite images before and after the 2008 earthquake were collected, including an IKONOS image in November 2002, two SPOT5 images in September 2006 and June 2008, a WorldView-2 image in August 2011, and a WorldView-1 image in April 2012 (Table 1). A $25 \mathrm{~m}$ resolution DEM was derived from a 1:50000 scale topographic map. Using RPCs and at least four GCPs for each image, orthorectification was done with a root mean square error of less than $2 \mathrm{~m}$ for all images based on the 2002 IKONOS image, which had the minimum off nadir angle of $4.2^{\circ}$.

Manual interpretation of buildings was carried out on the platform of ENVI 4.8 based on the shape, spectrum, texture, and other information of houses on the 2002 and 2011 images. Given the low economic activity of this mountainous rural area, the IKONOS image in 2002 and the WorldView image in 2011 could be used to represent the pre- and post-earthquake condition. Field survey revealed that the average size of pre- and post-quake buildings was greater than $4 \mathrm{~m} \times 4 \mathrm{~m}$. The footprint of each house was represented as a polygon by digitizing building outlines. Post-earthquake houses were also validated by field surveys in 2012 and 2013. Buildings destroyed by landslides during the 2008 earthquake and damages caused by debris flows and floods in 2012 were validated in selected areas along the valleys in the study area. Thirty-one buildings in Maanshi and 51 in Hejiashan were completely destroyed by landslides during the 2008 earthquake. Flood- and debris-affected buildings in 2013 were also surveyed and mapped based on GPS tracks with 185 and 65 buildings affected by floods and debris, respectively.

Along with sediment transportation and deposition, the riverbed provides a key link between landslides in the upstream basin and houses rebuilt on the lower streams. Riverbeds before and after the earthquake were interpreted based on very high-resolution images in 2002 and 2011. In these images, the riverbed was interpreted based on its tone in stereo images draped over the $25 \mathrm{~m}$ DEM. The riverbed in
2002 was defined to incorporate floodplains, which were covered by very little vegetation with similar elevation near the watercourse. The mapping of the riverbed in 2011 was based on image interpretation of texture, where deposited rocks of various sizes were obvious and confirmed with field validation in 2012 and 2013.

The landslides in 2008 and 2011 were interpreted using high-resolution images and validated by field surveys from September 2012. Coseismic landslides in 2008 were mapped by comparing two SPOT5 images pre- and post-earthquake and validated based on other existing landslide inventories in this area (Xu et al., 2014).

Field surveys from 2012 and 2013 showed significant accumulation of debris in the riverbed. Based on field measurements from August 2012 and September 2013, we selected buried houses at four sites located on the riverbed as reference points to estimate the depth change of deposits along the stream (Fig. 2). After the rainstorm in August 2013, the accumulation of debris in these locations on the riverbed rose from 1.4 to $3.2 \mathrm{~m}$. The rising and broadening river morphology show in combination that the amount of sediment deposition on the riverbed is substantial.

\section{Results}

The main surface rupture of the Wenchuan earthquake runs through the bottom of the Hongxi River valley in the study area (Xu et al., 2009). About $68.9 \%$ of the pre-seismic housing was located within $1000 \mathrm{~m}$ distance from the surface rupture. Within this distance, less than $10 \%$ of the total houses survived the major earthquake in 2008 (Zhao et al., 2012). Despite of this heavy damage along the surface rupture, an increased percentage of post-seismic houses up to $75.2 \%$ are located within $1000 \mathrm{~m}$ from the surface rupture. Major increase of post-seismic housing was observed between 50 and $250 \mathrm{~m}$ from the surface rupture (Fig. 3). The distances between housing and the surface rupture displayed a similar distribution for the post-seismic houses as pre-seismic ones. The number of these housing decreased dramatically with distance from the surface rupture, which reflected the distribution of the scarce construction space in the study area.

Because of the steep terrain, both pre- and post-earthquake houses are sparsely distributed within the study area. Based on overlay analysis, 145 houses were affected by coseismic landslides in 2008, including houses that were fully or partially covered by the landslides (Fig. 4a). Twenty-three landslides were identified as damage coseismic landslides that affected houses in the watershed. Two of these are listed within the top 20 fatal landslides of the Wenchuan earthquake: the Maanshi landslide and the Zhengjiashan landslide cluster (Yin, 2008). The spatial distribution of postearthquake houses differs from pre-earthquake houses, where some relocations were made from previously occupied locations to unoccupied new sites, the post-earthquake houses 

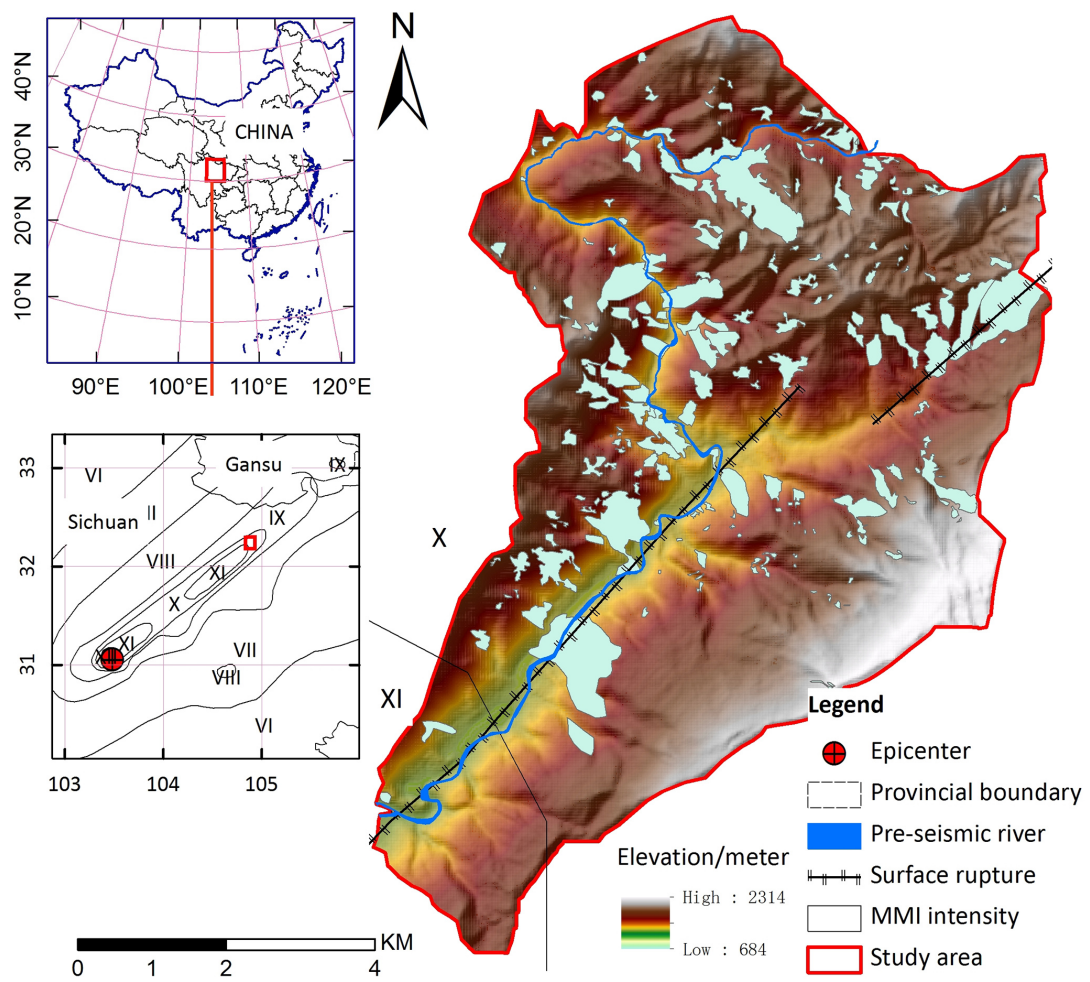

Coseismic landslides

Figure 1. Schematic map of the study area.
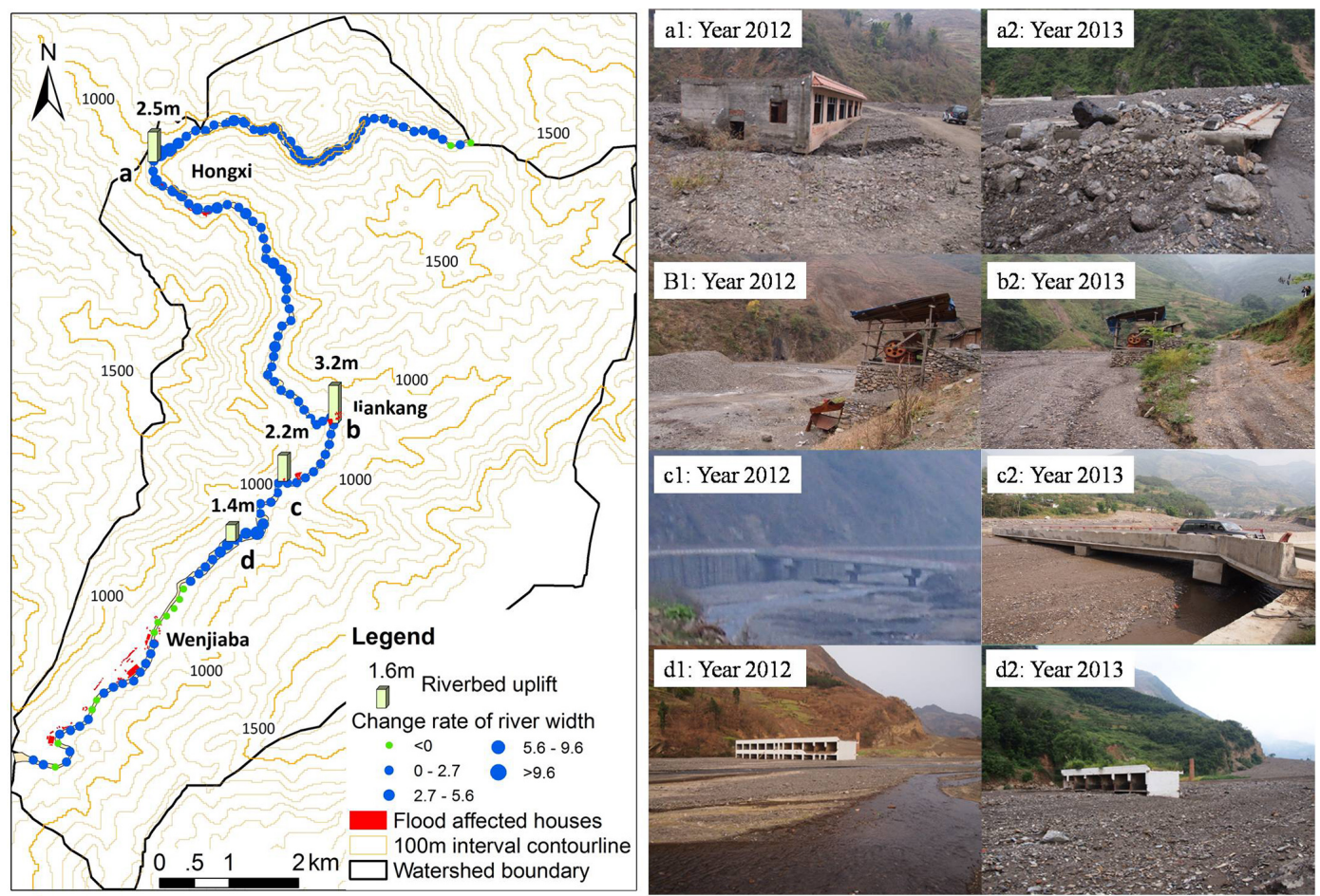

Figure 2. Accumulation of debris on the riverbed at four locations and distribution of flooded houses during the 2013 August flood (photos of a1, b1, c1, and d1 were taken in August 2012; a2, b2, c2, and d2 were taken in September 2013). 


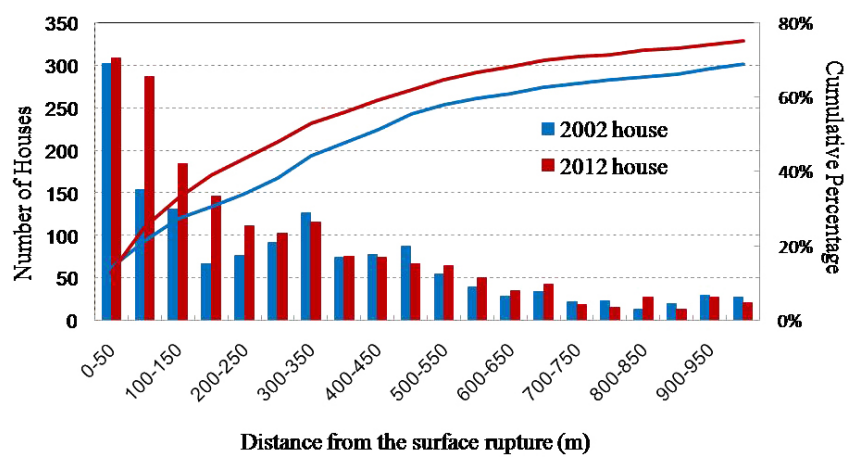

Figure 3. Houses distributions in different distance buffers from the surface rupture in the study area (bars for numbers of houses and curves for cumulative percentage of houses).

tend to cluster within major locations, and re-built housings clustered along riverbanks near Wenjiaba and east Jiankang (Fig. $4 \mathrm{~b}$ and c). Besides, major decreases of housing were observed east of Hongxi village and the movement of housing clusters from east of Jiankang to Jiankang is obvious. Compared to pre-earthquake buildings, the number of postearthquake houses increased from 2139 to 2371.

Figure $5 \mathrm{a}$ shows that regions with slopes of 30 to $35^{\circ}$ have the largest area of new and enlarged landslides, where there seem to be fewer new and enlarged landslides on gentle slopes. However, because of fewer areas with gentle slopes, a higher percentage of gentle slope areas between 5 to $15^{\circ}$, and steeper slopes above $40^{\circ}$, are threatened by enlarged landslides (Fig. 5b). More than $90 \%$ of the housing was located below $35^{\circ}$ both before and after the 2008 earthquake with large increases in post-earthquake houses on slopes gentler than $25^{\circ}$ (Fig. 5b).

Figure 6a shows that there are more enlarged than newly generated landslides on all elevation intervals. New and enlarged landslides occur mainly below $1000 \mathrm{~m}$ with fewer at higher elevations. Elevation in the watershed ranges from 684 to $2286 \mathrm{~m}$, where the altitude of the residential houses ranges from 688 to $1650 \mathrm{~m}$. The highest residential house pre- and post-earthquake was located near $1650 \mathrm{~m}$ at the eastern margin of the watershed. Relocated houses were mainly distributed at lower elevation near downstream Wenjiaba and Jiankang (Fig. 4b and c). Two main clusters of houses occurred at elevation intervals of 688 to 900 and 1000 to $1300 \mathrm{~m}$ for pre- and post-earthquake houses, respectively (Fig. 6b). Compared to the elevation of pre-earthquake houses, the major increase for post-earthquake houses occurs at elevations ranging from 688 to $800 \mathrm{~m}$, showing that the lower elevations were preferred for the rebuilding of houses. Above $1200 \mathrm{~m}$, fewer post-earthquake houses were built compared to the preearthquake situation.

The dominance of enlarged landslides over newly generated landslides indicates that most of the post-earthquake landslides are related to existing coseismic landslides. A greater percentage of new and enlarged landslides at lower elevation between 800 and $1100 \mathrm{~m}$ indicate that the low elevation areas are more susceptible to post-earthquake landslide activities. The active enlarged landslides on the lower slope gradients and elevations are caused by the downward movement of landslide debris to the valley bottom, where most post-earthquake reconstructed buildings become significantly susceptible to post-earthquake landslide activities.

Compared to the pre-earthquake water channel, an increase in river width was observed in the upstream area and a decrease in width in the downstream area (Fig. 7). We investigated the width of the pre- and post-earthquake water channel within this watershed from images and field surveys. Moving from the river mouth upstream with $300 \mathrm{~m}$ intervals, different intersections of riverbed were measured along the main riverbed (Fig. 7). We compared the pre- and post-earthquake riverbed widths, and the changes to the postearthquake riverbed are shown for each riverbed intersection in Fig. 7. After the earthquake, the riverbed width increased dramatically, especially in the upstream section and in segments of the downstream part, with three substantial increases at upper Hongxi and Jiankang villages (Fig. 2). However, a decrease in the riverbed width was also observed upstream Wenjiaba village. This decrease was caused by land reclamation from floodplains for industrial use, which was also observed in the field work. The most significant increase in riverbed width was located between Wenjiaba and Jiankang, where the terrain is flat and sediment was widely deposited.

Based on digitized and field-validated riverbed data in 2002 and 2011, the distances of houses from the main riverbed were calculated by buffer analysis for pre- and postearthquake conditions (Fig. 8). For every distance unit from the riverbank, a higher percentage of rebuilt houses were located within $70 \mathrm{~m}$ distance from the riverbank compared with the pre-earthquake housing, which places more postearthquake houses in flood areas during flood events, such as the August 2013 flood. Compared to $17 \%$ of houses located within $100 \mathrm{~m}$ of the riverbank before the earthquake, $23 \%$ of post-earthquake houses were located within $100 \mathrm{~m}$ of the riverbed after the reconstruction. This is most likely due to the trend of rebuilding towards lower elevation and gentler slope areas along riverbanks in this mountainous region.

Fieldwork conducted in September 2013 showed that flash floods affected houses distributes along the river mainly concentrated in three locations: Hongxi, Jiankang, and Wenjiaba (red polygons in Fig. 2). Most of the flood-affected areas reside along river channels, apart from a few others located in debris-filled valleys east of Jiankang. All three inundated areas are coupled with dramatic river width changes. Rebuilt houses in Hongxi and Shikan are located in the upstream area characterized by deep valleys, where the elevation contrast between houses and the river channel is low, whereas the flood-affected Wenjiaba area in the lower stream is located near the segments of decreased channel width (Fig. 2). 

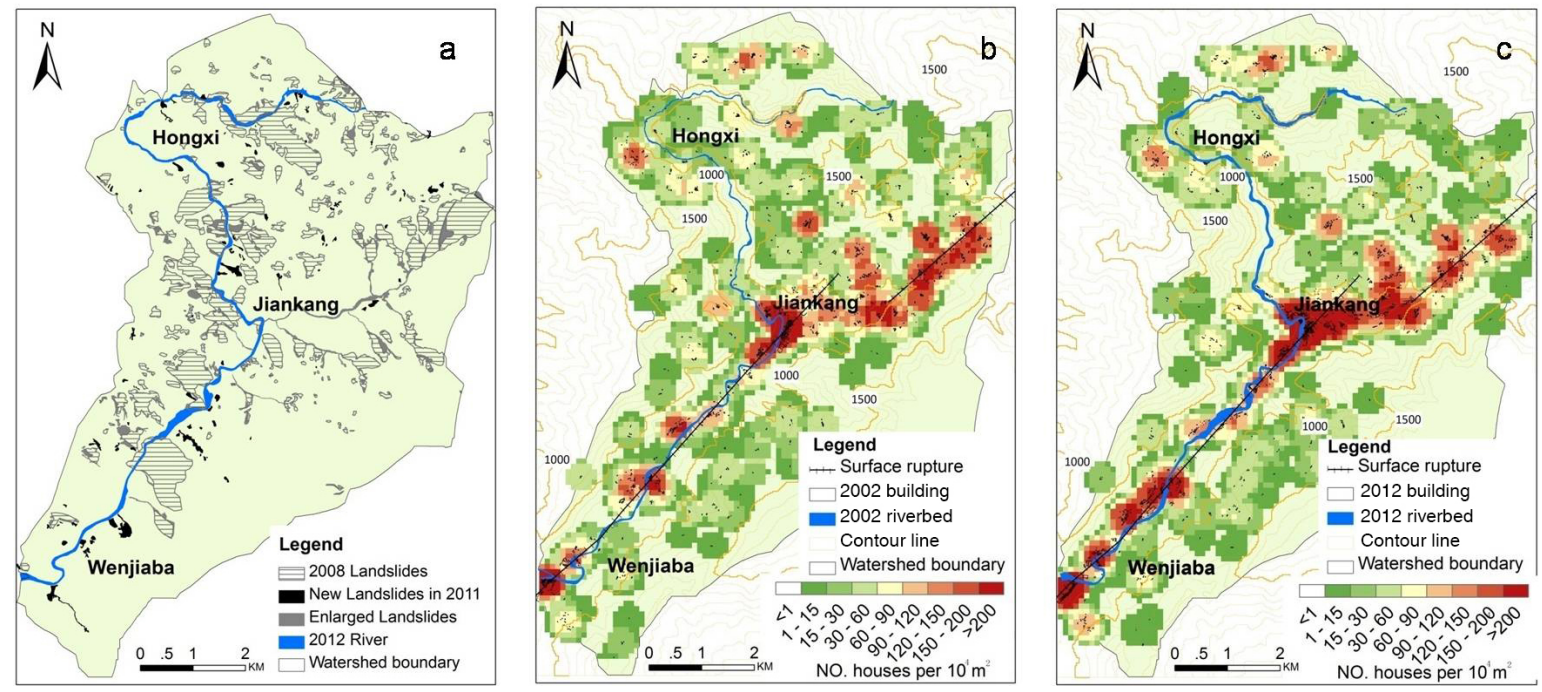

Figure 4. Spatial changes in landslides and buildings.
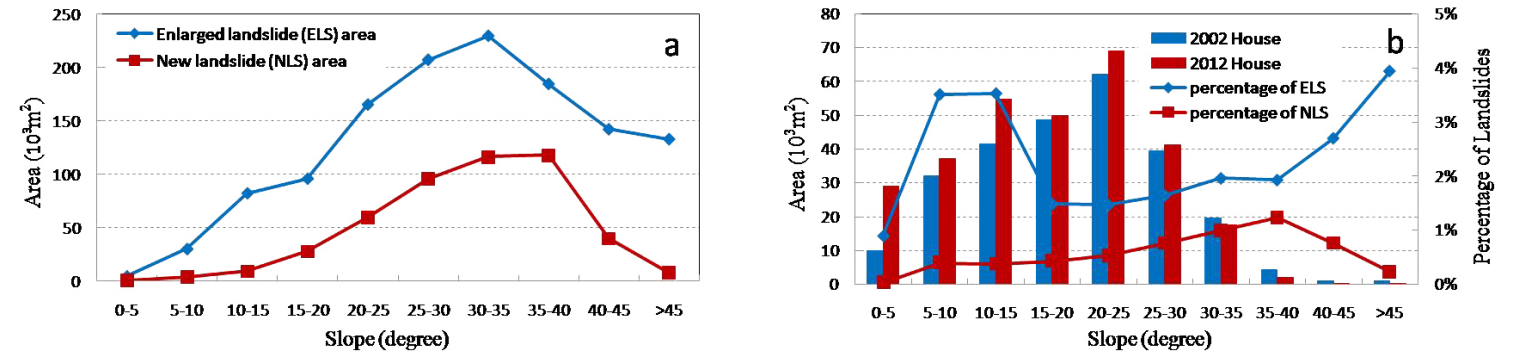

Figure 5. Distribution of new or enlarged landslides and buildings on different slope units.

\section{Discussion}

Although we only analyzed the lower part of the watershed, the study area covers over $90 \%$ of all coseismic landslides within the studied watershed, in particular the largest ones, which have connections to the riverbed. Based on fieldwork and satellite images, most small and shallow coseismic landslides were rapidly covered by vegetation, leaving most large, deep-seated landslides along the stream as the main debris sources to the riverbed.

Spatial analysis between landslides and houses at different times reveal that the geoenvironments and the elements at risk have changed over time. Before the earthquake, few landslides existed in the watershed and most of the landslides were shallow slides caused by road building, and debris flows originated from steep ridges along the deeply incised valley. Because of the monsoon climate of the region, there are no significant rainfall events, such as the cyclone sequences after the 1999 Taiwan earthquake (Lin et al., 2006). However, most of the rainfall events occur during the summer season from May to September, which have triggered many landslides (Tang et al., 2011). During the earthquake, there were widespread landslides in the study area and these coseismic landslides evolved into flow-like morphology 3 years after the main earthquake (Fig. 4a). The downward movements of hillslope materials have buried the previous riverbed and the nearby terrace (Fig. 4a), leading to the common events of river overflow in the watershed. At the same time, flat areas in the watershed were concentrated along both riverbanks, where most new houses were built (Fig. 4c). The similar trend between the rebuilt houses and the patterns of debris movement from landslides indicate that more flood events might occur in the region.

\section{Conclusions}

The impact of an earthquake in a mountain region can persist for a long time and can change from landslides to debris flows in the valley and flash floods near the river course. The increased area of rebuilt houses on the gentle slopes and lower altitude places more newly built houses at risk of debris flows and flash floods as the riverbed is continually filled by debris from coseismic landslides. The main geohazards in this watershed have gradually changed from landslides and debris flows to more frequent flash floods. Comparing 

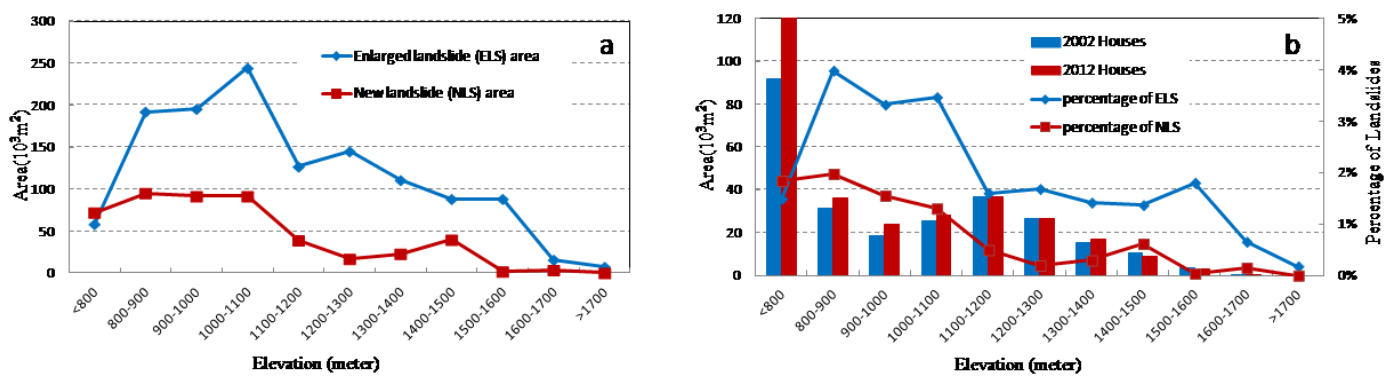

Figure 6. Distribution of new or enlarged landslides and buildings on different elevation units.
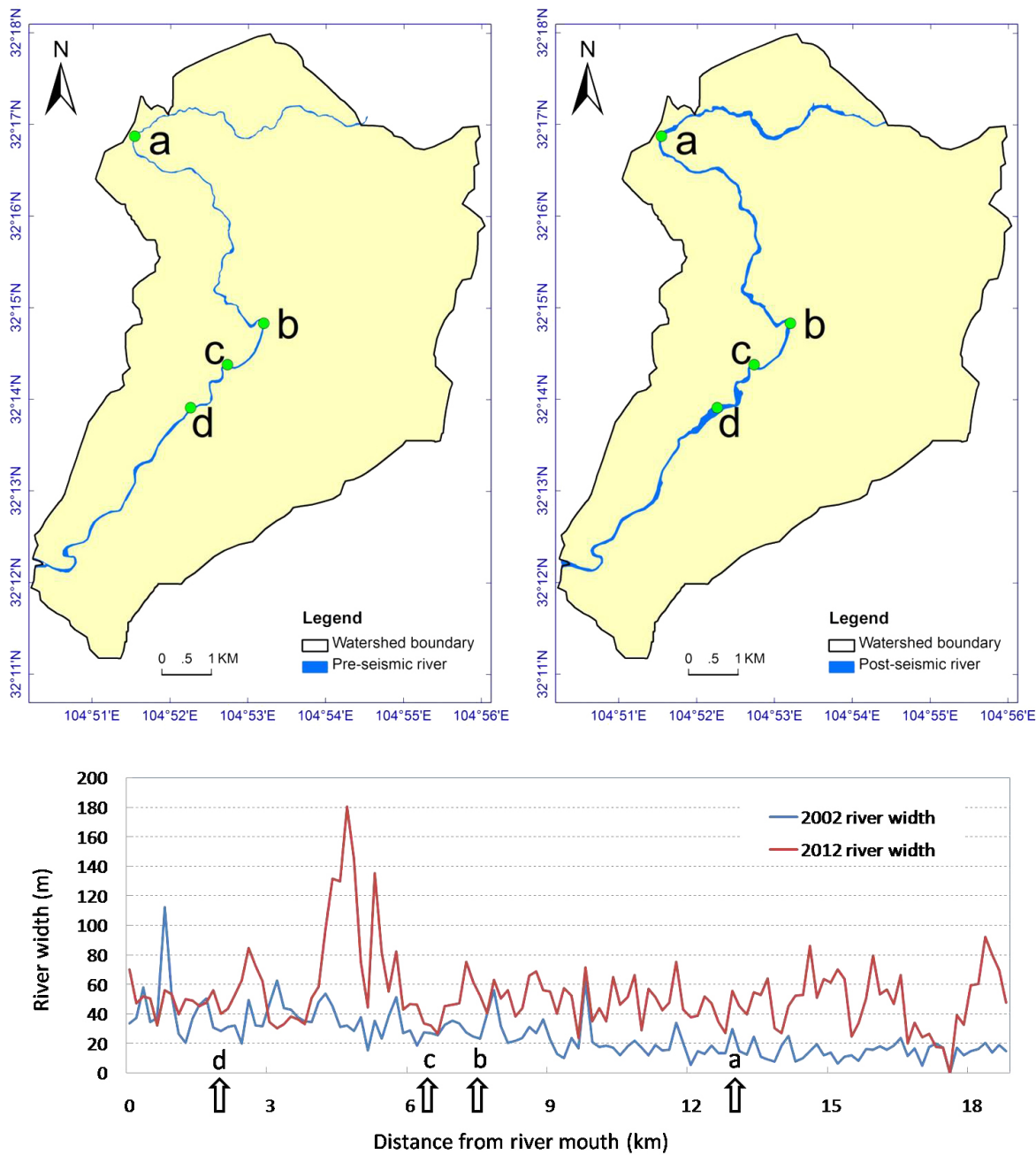

Figure 7. Riverbed width change before and after the earthquake.

the distribution of landslide debris and houses pre- and postearthquake on the Fujiang River tributary, we find the following:

1. Post-seismic houses were built closer to the surface ruptures and concentrated on gentler slopes, lower elevation areas, and closer to the riverbed.
2. After the earthquake, there were more enlarged than newly generated landslides. Material originated mainly from coseismic landslides. Landslide back-scarp retreat was the main landslide activity of enlarged landslides.

3. The width and depth of the riverbed have changed dramatically because of material from landslides. The 


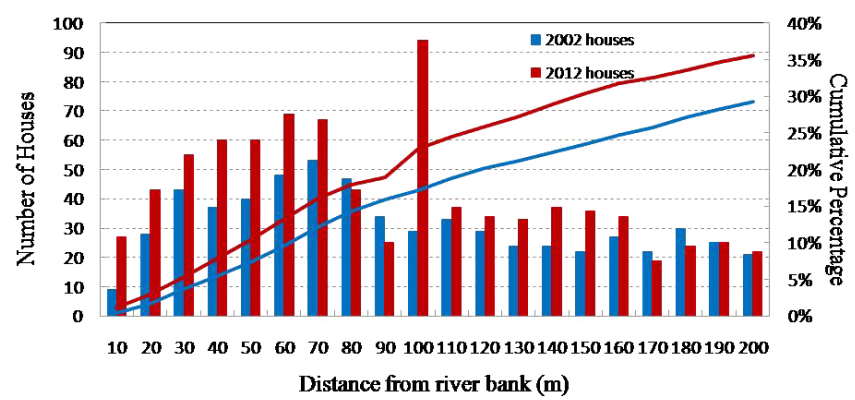

Figure 8. Distribution of housing in different distance buffers from the river in the study area.

changing width and uplift of the riverbed increase the risk of flash floods in the watershed.

Because of the limited land resources for reconstruction after the Wenchuan earthquake, the rapid post-seismic reconstruction process has encountered significant challenges for future seismic, flood, and other related geohazards. We predict that this area might suffer long-term geohazards in the future, and the task to prevent geohazards would be a high priority.

Acknowledgements. This work was sponsored by the National Natural Science Foundation of China under grant 41101505, by the State Key Laboratory of Earth Surface Processes and Resource Ecology under grant 2014-ZY-05, and by the National Key Technology R\&D Program 2012BAK10B03. W. Yang's research at the University of Twente was funded by the "Joint Ph.D. Scholarship of the China Scholarship Council" (no. 201306040026). The authors would like to thank Michiel Damen at ITC, University of Twente, for assisting with the interpretation of the landslide data.

Edited by: T. Glade

Reviewed by: C. Xu and one anonymous referee

\section{References}

Atta-ur-Rahman, Khan, A. N., Collins, A. E., and Qazi, F.: Causes and extent of environmental impacts of landslide hazard in the Himalayan region: a case study of Murree, Pakistan, Nat. Hazards, 57, 413-434, doi:10.1007/s11069-010-9621-7, 2010.

Atta-ur-Rahman, Khan, A. N., and Collins, A. E.: Analysis of landslide causes and associated damages in the Kashmir Himalayas of Pakistan, Nat. Hazards, 71, 803-821, doi:10.1007/s11069013-0918-1, 2013.

Chen, C.-Y.: Sedimentary impacts from landslides in the Tachia River Basin, Taiwan, Geomorphology, 105, 355-365, doi:10.1016/j.geomorph.2008.10.009, 2009.

Cheng, J. D., Huang, Y. C., Wu, H. L., Yeh, J. L., and Chang, C. H.: Hydrometeorological and landuse attributes of debris flows and debris floods during typhoon Toraji, 2930 July 2001 in central Taiwan, J. Hydrol., 306, 161-173, doi:10.1016/j.jhydrol.2004.09.007, 2005.
Cui, P., Chen, X.-Q., Zhu, Y.-Y., Su, F.-H., Wei, F.-Q., Han, Y.S., Liu, H.-J., and Zhuang, J.-Q.: The Wenchuan Earthquake (12 May 2008), Sichuan Province, China, and resulting geohazards, Nat. Hazards, 56, 19-36, doi:10.1007/s11069-009-9392-1, 2011.

Dadson, S. J., Hovius, N., Chen, H., Dade, W. B., Hsieh, M.-L., Willett, S. D., Hu, J.-C., Horng, M.-J., Chen, M.-C., and Stark, C. P.: Links between erosion, runoff variability and seismicity in the Taiwan orogen, Nature, 426, 648-651, 2003.

Dunford, M. and Li, L.: Earthquake reconstruction in Wenchuan: Assessing the state overall plan and addressing the "forgotten phase", Appl. Geogr., 31, 998-1009, doi:10.1016/j.apgeog.2011.01.001, 2011.

Fan, X., Tang, C. X., van Westen, C. J., and Alkema, D.: Simulating dam-breach flood scenarios of the Tangjiashan landslide dam induced by the Wenchuan Earthquake, Nat. Hazards Earth Syst Sci., 12, 3031-3044, doi:10.5194/nhess-12-3031-2012, $2012 \mathrm{a}$.

Fan, X., van Westen, C. J., Korup, O., Gorum, T., Xu, Q., Dai, F., Huang, R., and Wang, G.: Transient water and sediment storage of the decaying landslide dams induced by the 2008 Wenchuan earthquake, China, Geomorphology, 171, 58-68, 2012b.

Gorum, T., Fan, X., van Westen, C. J., Huang, R. Q., Xu, Q., Tang, C., and Wang, G.: Distribution pattern of earthquake-induced landslides triggered by the 12 May 2008 Wenchuan earthquake, Geomorphology, 133, 152-167, 2011.

Huang, R.: After effect of geohazards induced by the Wenchuan Earthquake, Journal of Engineering Geology, 19, 145-151, 2011.

Jha, A. K. and Duyne, J. E.: Safer homes, stronger communities: a handbook for reconstructing after natural disasters, World Bank Publications, Washington DC, 7-21, 2010.

Johnson, C.: Strategic planning for post-disaster temporary housing, Disasters, 31, 435-458, 2007.

Keefer, D. K.: The importance of earthquake-induced landslides to long-term slope erosion and slope-failure hazards in seismically active regions, Geomorphology, 10, 265-284, 1994.

Khan, S. F., Kamp, U., and Owen, L. A.: Documenting five years of landsliding after the 2005 Kashmir earthquake, using repeat photography, Geomorphology, 197, 45-55, doi:10.1016/j.geomorph.2013.04.033, 2013.

Khattak, G. A., Owen, L. A., Kamp, U., and Harp, E. L.: Evolution of earthquake-triggered landslides in the Kashmir Himalaya, northern Pakistan, Geomorphology, 115, 102-108, doi:10.1016/j.geomorph.2009.09.035, 2010.

Koi, T., Hotta, N., Ishigaki, I., Matuzaki, N., Uchiyama, Y., and Suzuki, M.: Prolonged impact of earthquake-induced landslides on sediment yield in a mountain watershed: The Tanzawa region, Japan, Geomorphology, 101, 692-702, doi:10.1016/j.geomorph.2008.03.007, 2008.

Kozin, F. and Zhou, H.: System study of urban response and reconstruction due to earthquake, J. Eng. Mech.-Asce., 116, 1959$1972,1990$.

Lin, C.-W., Liu, S.-H., Lee, S.-Y., and Liu, C.-C.: Impacts of the Chi-Chi earthquake on subsequent rainfallinduced landslides in central Taiwan, Eng. Geol., 86, 87-101, doi:10.1016/j.enggeo.2006.02.010, 2006.

Lin, W.-T., Chou, W.-C., and Lin, C.-Y.: Earthquake-induced landslide hazard and vegetation recovery assessment using remotely sensed data and a neural network-based classifier: a case study in central Taiwan, Nat. Hazards, 47, 331-347, doi:10.1007/s11069008-9222-x, 2008. 
Mao, H., Zhang, X., and Wang, Z.: Design tactics of post-disaster urban renaissance - take the reconstruction plan of Nanba town, Pingwu as an example, New Architecture, 104-107, 2009.

Quarantelli, E. L.: Sheltering and housing after major community disasters: case studies and general observations, Washington DC, 72-74, 1982.

Saba, S. B., van der Meijde, M., and van der Werff, H.: Spatiotemporal landslide detection for the 2005 Kashmir earthquake region, Geomorphology, 124, 17-25, doi:10.1016/j.geomorph.2010.07.026, 2010.

Schwendtner, B., Papathoma-Köhle, M., and Glade, T.: Risk evolution: how can changes in the built environment influence the potential loss of natural hazards?, Nat. Hazards Earth Syst. Sci., 13, 2195-2207, doi:10.5194/nhess-13-2195-2013, 2013.

Shi, P.: Theory and practice of disaster study, Journal of Natural Disasters, 5, 6-14, 1996.

Sudmeier-Rieux, K., Jaboyedoff, M., Breguet, A., and Dubois, J.: The 2005 Pakistan Earthquake Revisited: Methods for Integrated Landslide Assessment, Mt. Res. Dev., 31, 112-121, doi:10.1659/mrd-journal-d-10-00110.1, 2011.

Tang, C., Zhu, J., Qi, X., and Ding, J.: Landslides induced by the Wenchuan earthquake and the subsequent strong rainfall event: A case study in the Beichuan area of China, Eng. Geol., 122, 22-33, doi:10.1016/j.enggeo.2011.03.013, 2011.

UNDRO: Shelter after disaster: Guidelines for assistance, United Nations, 46-47, New York, 1982.
Wang, M., Yang, W., Shi, P., Xu, C., and Liu, L.: Diagnosis of Vegetation Recovery in Mountainous Regions After the Wenchuan Earthquake, IEEE J. Sel. Top. Appl., 7, 3029-3037, doi:10.1109/JSTARS.2014.2327794, 2014.

Wu, J. Y. and Lindell, M. K.: Housing Reconstruction After Two Major Earthquakes: The 1994 Northridge Earthquake in the United States and the 1999 Chi-Chi Earthquake Earthquake in Taiwan, Disasters, 28, 63-81, 2004.

Xin, H.: Slew of Landslides Unmask Hidden Geological Hazards, Science, 330, p. 744, 2010.

Xu, C., Xu, X., Yao, X., and Dai, F.: Three (nearly) complete inventories of landslides triggered by the 12 May 2008 Wenchuan Mw 7.9 earthquake of China and their spatial distribution statistical analysis, Landslides, 11, 441-461, 2014.

Xu, X. W., Wen, X. Z., Yu, G. H., Chen, G. H., Klinger, Y., Hubbard, J., and Shaw, J.: Coseismic reverse- and oblique-slip surface faulting generated by the $2008 \mathrm{Mw} 7.9$ Wenchuan earthquake, China , Geology, 37, 515-518, 2009.

Yin, Y.: Researches on the geo-hazards triggered by Wenchuan earthquake, Sichuan [J], J. Eng. Geol., 4, 7-12, 2008.

Zhao, J., Wu, J., Shi, L., and Liu, Y.: Distribution of Seismic Damaged Buildings along the Trace of Ground Surface Rupture Caused by the $M_{\mathrm{S}} 8.0$ Wenchuan Earthquake, Advances in Geosciences (21633967), 2, 1-15, 2012. 